\title{
¿VALE LA PENA INVERTIR EN EDUCACIÓN SUPERIOR DE CALIDAD?
}

\author{
Lorena Neria de Girarte \\ Universidad de Montemorelos
}

La educación superior es costosa pero en la medida en que las sociedades comprendan que debe entenderse como una inversión más que como un gasto podrán enfrentar mejor otros desafíos (Pacheco, 2016). Así lo expresa la estrategia de educación 2020 del Banco Mundial (2011):

El crecimiento, el desarrollo y la reducción de la pobreza dependen de los conocimientos y las capacidades que adquieren las personas, no de la cantidad de años que pasan en un aula. A nivel individual, si bien un diploma puede abrir las puertas del empleo, las habilidades de cada trabajador determinan su productividad y su capacidad de adaptarse a nuevas tecnologías y oportunidades. Además, los conocimientos y las capacidades contribuyen a la posibilidad de cada persona de tener una familia saludable y educada y una vida cívica activa. (p. 3)

Elegir en cuál universidad estudiar es más que buscar un título profesional, siendo que éste ya no es suficiente. Es necesario asegurarse de que la institución universitaria brinda la oportunidad de experiencias de aprendizaje orientadas al desarrollo de competencias en un ambiente que permita el desarrollo

Lorena Neria de Girarte, UM Virtual, Universidad de Montemorelos, México.

La correspondencia concerniente a este artículo puede ser enviada a Lorena Neria de Girarte, correo electrónico: ead@um.edu.mx integral del estudiante y lo convierta en un profesional más "empleable" y más habilitado para contribuir en el entorno social en el que se desarrolla.

Crear un modelo educativo que asegure egresados con ese perfil requiere una inversión fuerte de recursos humanos y financieros, ya que la calidad cuesta. En México existen muchas escuelas privadas y públicas, lo cual resulta en una oferta de programas y costos variados. A pesar de ello, cualquier programa implicará un importante desembolso económico ("Costo de la educación en México y el mundo", 2015). De acuerdo al análisis Compara Carreras 2015 del Instituto Mexicano para la Competitividad (IMCO, 2015), en los últimos años, el costo de colegiatura en universidades privadas ha crecido, por encima de la inflación, de \$332,641.47 en 2013 a $\$ 408,945.86$ en 2014.

Por otro lado, la Universidad Nacional Autónoma de México (UNAM, 2015) declara que el costo por alumno en 2015 fue de $\$ 59,577.00$, es decir, aun la educación que "no cuesta" requiere una fuerte inversión por parte del estado.

Según datos de la Organización para la Cooperación y el Desarrollo Económico (OCDE, 2015), en México solamente 3 de cada 10 jóvenes en edad de obtener educación superior acceden a ella. Un problema adicional que se suma a esta cifra es que algunos egresados universitarios carecen de los conocimientos y habilidades que están deman- 


\section{¿VALE LA PENA INVERTIR EN EDUCACIÓN SUPERIOR DE CALIDAD?}

dando sus posibles empleadores (Centro de Investigación para el Desarrollo [CIDAC], 2011).

Esto evidencia, por tanto, dos desafíos: (a) el acceso a la universidad y (b) la calidad académica de las instituciones para preparar profesionales cada vez más "empleables" de acuerdo con las demandas del mercado.

Por ello, al pensar en estudios universitarios, es necesario tomar una decisión inteligente y hacer las siguientes consideraciones: (a) qué carrera elegir y (b) en cuál institución estudiar.

Respecto de la carrera profesional a elegir, el estudio Compara Carrera 2015 (IMCO, 2015) agregó un nuevo indicador para medir la calidad de la inversión en una carrera profesional. Este considera dos factores: (a) el retorno de la inversión en el tiempo y (b) el factor de riesgo, el cual se integra por las variables de desempleo, informalidad y población desanimada. Es decir, es importante considerar si la carrera elegida es una inversión de tiempo y dinero que vale la pena, porque ofrecerá oportunidades favorables para el futuro profesional.

Al decidir qué institución elegir, el costo de la colegiatura no debería ser el único factor a considerar. El IMCO (2015) agrega que hay una proliferación de universidades de baja calidad. En México, cada año se revocan en promedio 1.180 programas de licenciatura, pero aparecen 2.000 más, que generalmente cuentan con escasa calidad académica.

La factibilidad de la institución de preparar profesionales con altos índices de "empleabilidad" y capacidad de aporte a la sociedad debería ser el principal factor a considerar al elegir la institución educativa.

Con todo, los especialistas afirman que estudiar sigue siendo una buena in- versión, en México (Cruz Domínguez, 2013). Según datos de la OCDE (2015) un profesional gana en promedio un $50 \%$ más que una persona con educación media superior.

Así, la calidad académica y la pertinencia de su oferta educativa constituyen un buen termómetro para definir qué institución elegir (Cruz Domínguez, 2013). Además, estudiar en instituciones universitarias que acreditan su calidad académica ofrece otros beneficios muy atractivos y que potencian las oportunidades a futuro, tales como acceso a becas y créditos del gobierno, acceso a convenios internacionales del gobierno y de la institución educativa que brindan oportunidades para experiencias de intercambio y participación en proyectos de servicio, vinculación a programas gubernamentales de investigación, mayores posibilidades de empleo y mejor remuneración salarial y homologación de títulos internacionales.

La clave consistirá en escoger un programa que desarrolle competencias orientadas a la productividad laboral y a la capacidad de adaptarse a nuevas tecnologías y oportunidades, que habiliten al futuro profesional para emprender proyectos de innovación y de servicio que impacten sobre sus entornos de influencia y que formen ciudadanos que aporten a la sociedad una familia saludable y educada y una vida cívica activa, como lo sugiere el Banco Mundial (2011) en su estrategia de educación 2020.

\section{Referencias}

Banco Mundial. (2011). Aprendizaje para todos. Invertir en los conocimientos y las capacidades de las personas para fomentar el desarrollo. Recuperado de http://siteresources .worldbank.org/EDUCATION/Resources/ ESSU/463292-1306181142935/Spanish_ Exec_Summary_2020_FINAL.pdf 


\section{GIRARTE}

Centro de Investigación para el Desarrollo. (2011, 24 de agosto). Ganan profesionistas $74 \%$ más que personas con preparatoria. Boletín de prensa. Recuperado de http://cidac.org/esp/ uploads/1/boletinPROFESIONISTAS_1.pdf

Costo de la educación en México y el mundo. ¿Qué conviene más? (2014, 20 de junio). El Semanario. Recuperado de http://elsemanario .com/59022/costo-de-la-educacion-en-mexico -y-el-mundo-que-conviene-mas/

Cruz Domínguez, A. (2013, 10 de abril). Los beneficios de estudiar un posgrado. El economista. Recuperado de http://eleconomista .com.mx/finanzas-personales/2013/04/10/ beneficios-estudiar-posgrado

Instituto Mexicano para la Competitividad. (2015). Compara carreras 2015. Una herramienta sobre las consecuencias económicas de escoger una carrera. Recuperado de http://imco.org.mx/ wp-content/uploads/2015/08/2015-Compara Carreras-Presentacion.pdf
Organización para la Cooperación y el Desarrollo Económico. (2015). México: Nota país. Panorama de la educación 2015. Recuperado de http://www.oecd.org/mexico/Education-at-aglance-2015-Mexico-in-Spanish.pdf

Pacheco, R. (2016, 15 de enero). Educación superior es una inversión no un gasto: FMC. Pulso. Recuperado de http://pulsoslp.com .mx/2016/01/15/educacion-superior-es-unainversion-no-un-gasto-fmc/

Universidad Nacional Autónoma de México. (2015). Estadística de gasto por alumno. Recuperado de http://www.estadistica.unam.mx/series_inst/ xls/c38\%20gasto\%20por\% 20alumno.xls

Recibido: 3 de agosto de 2015

Revisado: 20 de agosto de 2015 Aceptado: 2 de noviembre de 2015 